\title{
Cafeicultura em Rondônia: Circuito Espacial de Produção, Modernização e Subordinação
}

\author{
Coffee cultivation in Rondônia: Production Space Circuit, modernization and \\ subordination \\ Caficultura en Rondônia: Circuito Espacial de Producción, Modernización Y \\ Subordinación
}

Tiago Roberto Silva Santos ${ }^{1}$ Ricardo Gilson da Costa Silva²

RESUMO: A cafeicultura tem passado por transformações técnico-produtivas em Rondônia, que resulta da atuação direta de instituições públicas e privadas, responsáveis pelo fluxo material e imaterial da produção agrícola. A partir dos conceitos de circuito espacial da produção e círculo de cooperação buscamos analisar a organização espacial da cafeicultura, contextualizando o processo de modernização tecnológica na escala estadual. A metodologia da pesquisa foi realizada com sistematização bibliográfica e dados obtidos em trabalho de campo efetivado no município de Cacoal (RO). Dessa forma, conclui-se que a transformação agrícola indica o processo geral de subordinação da agricultura familiar ao capital, criando uma psicosfera do café, com formação de regiões produtivas, indicando que as variáveis do mercado nacional e global atingem as áreas de fronteira agrícola.

Palavras-Chave: Cafeicultura. Circuito Espacial de Produção. Círculo de Cooperação. Modernização. Rondônia.

ABSTRACT: Coffee cultivation has undergone technical-productive transformations in Rondônia, which results from the direct action of public and private institutions responsible for the material and immaterial flow of agricultural production. From the concepts of spatial circuit production and the circle of cooperation we seek to analyze the spatial organization of coffee cultivation, contextualizing the process of technological modernization at the state level. The methodology of the research was carried out with bibliographical systematization and data obtained in field work carried out in the municipality of Cacoal (RO). Therefore, it has been concluded that agricultural transformation indicates the general process of subordination of family agriculture to the capital, creating a coffee psychosphere, with the formation of productive regions, indicating that variables of the national and global market reach the areas of the agricultural frontier.

Keywords: Coffee cultivation. Production Space Circuit. Circle of Cooperation. Modernization. Rondônia.

RESUMEN: La caficultura ha pasado por transformaciones técnico-productivas en Rondônia, que resulta de la actuación directa de instituciones públicas y privadas, responsables por el flujo material e inmaterial de la producción agrícola. A partir de los conceptos de circuito espacial de la producción y círculo de cooperación buscamos analizar la organización espacial de la caficultura, contextualizando el proceso de modernización tecnológica en la escala estadual. La metodología de la investigación fue realizada con sistematización bibliográfica y datos obtenidos en trabajo de campo efectuado en el

Geografia (Londrina) v. 26. nº. 2. p. $145-163$, jul/dez, 2017. 
municipio de Cacoal (RO). De esta forma, se concluye que la transformación agrícola indica el proceso general de subordinación de la agricultura familiar al capital, creando una psicosfera del café, con formación de regiones productivas, indicando que las variables del mercado nacional y global alcanzan las áreas de frontera agrícola.

Palabras-Clave: Caficultura. Circuito Espacial de Producción. Círculo de Cooperación. Modernización. Rondônia.

\section{INTRODUÇÃO}

Localizado na Amazônia Ocidental, o estado de Rondônia é produto espacial da fronteira agrícola brasileira na floresta amazônica, que incorporou áreas das atividades produtivas extrativistas para a produção agropecuária destinada às demandas do mercado globalizado. Dentre os produtos introduzidos na região amazônica o café tomou grande importância na transformação do uso espacial rondoniense, após o processo de colonização dirigido pelo Governo Federal, que incentivou intenso fluxo migratório para o estado, resultando em acelerada substituição de áreas de floresta por lavouras de café e pecuária.

Introduzida pelos migrantes que chegavam a Rondônia, a cafeicultura teve importante papel social com as famílias que oriundas de estados produtores de café, traziam suas práticas para a nova terra, permitindo assim sua territorialização. Esta atividade além de importância social ganhou também protagonismo econômico, elevando Rondônia entre os principais produtores de café do país.

Diante desta relevância geográfica, buscamos compreender a organização espacial da atividade cafeeira em Rondônia através da análise de sua participação no cenário nacional e internacional, a partir dos agentes responsáveis pela circulação do produto. Além disso, propomos uma análise espaço-temporal sobre a produção de café em Rondônia, identificando os processos de modernização técnica que esta atividade experimentou e como isso se reflete na qualidade e produtividade do café. Por fim, buscamos uma análise sobre a subordinação dos agricultores familiares ao capital comercial e industrial a partir da formação de uma psicosfera ${ }^{3}$ (SANTOS, 2014b) voltada à modernização técnica do café em Rondônia.

Portanto, para atingir tais objetivos, organizamos este trabalho em três partes, além desta introdução e das considerações finais. Na primeira parte, apontamos como a globalização promove transformações no uso do espaço, formando uma divisão territorial do trabalho a partir da expansão, ainda que em manchas, do meio técnico-científicoinformacional (SANTOS, 2014b), o que gera áreas especializadas e como consequência se tem a formação de circuitos espaciais de produção. A partir dessa abordagem conceitual, buscamos entender, através de levantamento bibliográfico e de dados estatísticos 
disponibilizados pelos órgãos oficiais, como está organizado o circuito espacial de produção e o círculo de cooperação da produção do café no Brasil e em Rondônia (SANTOS, 1994).

$\mathrm{Na}$ segunda parte apresentamos o processo de modernização da cafeicultura em Rondônia, utilizando um enfoque espaço-temporal que contribui para a compreensão da incorporação do espaço rondoniense à produção voltada ao mercado, bem como a introdução da cultura cafeeira e os avanços técnicos incorporados a esta atividade, melhorando sua qualidade e produtividade em Rondônia.

Por fim, na terceira parte fizemos apontamentos sobre as relações entre o capital e o Estado na condução da modernização tecnológica da cafeicultura, e o processo de subordinação da agricultura familiar através da atuação de agentes públicos e privados do círculo de cooperação, que no âmbito da psicosfera do café submete a atividade familiar à lógica do mercado nacional.

Assim, baseado em levantamento bibliográfico e dados adquiridos em trabalho de campo, acreditamos conseguir obter um panorama sobre a organização espacial da cafeicultura e a subordinação da agricultura familiar em Rondônia.

\section{CIRCUITO ESPACIAL DE PRODUÇÃO DO CAFÉ EM RONDÔNIA}

O atual momento de globalização é resultado do desenvolvimento histórico do capitalismo, cujas bases produtivas e tecnológicas promovem no espaço a formação de um meio técnico-científico-informacional (SANTOS, 2014b; SANTOS; SILVEIRA, 2008), possibilitando a dispersão espacial das diversas etapas do sistema produtivo. Assim, a produção deixa de estar concentrada em poucos pontos no planeta, mas distribuídas normalmente nos países periféricos e controladas pelos grandes centros hegemônicos.

Nessa geografia emergente o resultado da globalização é a intensificação da divisão territorial do trabalho, promovendo nas diversas escalas geográficas a formação de um mosaico de áreas especializadas em ramos produtivos diferentes (CASTILLO; FREDERICO, 2010; SILVEIRA, 2011). Além disso, nem sempre os locais da produção agropecuária são os mesmos da industrialização e/ou do consumo, sendo necessária a implantação de um conjunto de fixos e fluxos ${ }^{4}$ (SANTOS, 2014b) que permitam a mobilidade da mercadoria para onde estão localizadas as indústrias, e somente depois serem distribuídas para o consumo.

Como forma de compreender tais dinâmicas vários geógrafos propõem à análise o conceito de circuito espacial de produção (SANTOS, 1994 e 2014a; SANTOS; SILVEIRA, 2008; CASTILLO; FREDERICO, 2010; FREDERICO; CASTILLO, 2004; SILVEIRA, 2011), uma abordagem geográfica que permite verificar a organização espacial da produção e da circulação material e imaterial que formam os fluxos de bens, capital, informação, normas, 
objetos técnicos e etc., demonstrando a espacialidade e a articulação do sistema produtivo. Sobre isso, Santos (1994, p. 49) destaca:

O mundo encontra-se organizado em subespaços articulados dentro de uma lógica global. Não podemos mais falar em circuitos regionais de produção.[...] temos que falar em circuitos espaciais da produção. Estes seriam as diversas etapas pelas quais passariam um produto, desde 0 começo do processo de produção até chegar ao consumo final.

A partir desse conceito apontamos o papel da cafeicultura brasileira, que se destaca no cenário mundial como principal exportador de café (CECAFÉ, 2016), considerando que a produção se realiza em várias regiões do território brasileiro, o que resulta na criação de sistemas de objetos que possibilitam a circulação da mercadoria até as indústrias ou aos portos para exportação.

Assim, temos no circuito produtivo do café vários agentes espacializados, responsáveis por alguma etapa da produção. Santos (1994) alerta que em uma mesma área se pode ter vários circuitos de produção e também em uma mesma região distintas fases do processo produtivo, como a produção e o beneficiamento, e/ou a industrialização. Porém, isso não é uma regra, visto que o aumento da capacidade de circulação material (produto), imaterial (informações, normas) e da globalização, as distintas etapas do processo não precisam necessariamente estarem próximas (FREDERICO; CASTILLO, 2004).

Com relação ao café a atividade no Brasil alcançou seu auge ainda no século XIX e início do XX, concentrando-se principalmente nos estados do Rio de Janeiro, São Paulo, Paraná e Espírito Santo, que tiveram a implantação em suas regiões de um conjunto de objetos técnicos que contribuíram substancialmente para ampliar a produção agrícola. Soma-se as indústrias beneficiadoras e armazéns, além das rodovias e ferrovias que ligavam o interior produtor aos portos, inclusive promovendo novas colonizações, como no oeste de São Paulo e norte do Paraná, transformando assim o uso do espaço geográfico para tal atividade (ORTEGA; JESUS, 2012).

A partir da década de 1960, buscando melhorias na produção, o Instituto Brasileiro do Café (IBC) criou o Grupo Executivo de Racionalização da Cafeicultura (GERCA), que incentivou a substituição dos cafeeiros tradicionais por outros que permitissem maior produtividade, incorporando à produção tecnologias da chamada revolução verde (ORTEGA; JESUS, 2012). No entanto, no Paraná e em São Paulo, grande área da cafeicultura foi substituída por outras culturas, visto que as condições edafoclimáticas geravam inúmeras baixas na produção, principalmente devido às geadas. Com isso a produção cafeeira passou a se dispersar pelo território brasileiro, tendo como principais áreas o sul e sudoeste de Minas Gerais (FREDERICO; CASTILLO, 2004; ORTEGA; JESUS, 
2012). Após sua espacialização em Minas Gerais, o café ainda expandiu para Rondônia e também para o oeste da Bahia, ampliando assim a sua abrangência no território nacional (Figura 1).

Porém, nem todas as áreas produtoras passaram, desde o início, a fazerem parte do circuito espacial de produção do café, pois não estavam interligadas à circulação da produção e nem ao capital industrial, tratando-se de produções locais, como no caso de Rondônia, durante as décadas de 1970 e 1980, quando o café foi introduzido, passando a ter mais uma função social e de territorialização de agricultores familiares, do que necessariamente expressiva relevância econômica no comércio nacional.

Figura 1 Produção de café no Brasil (2014)

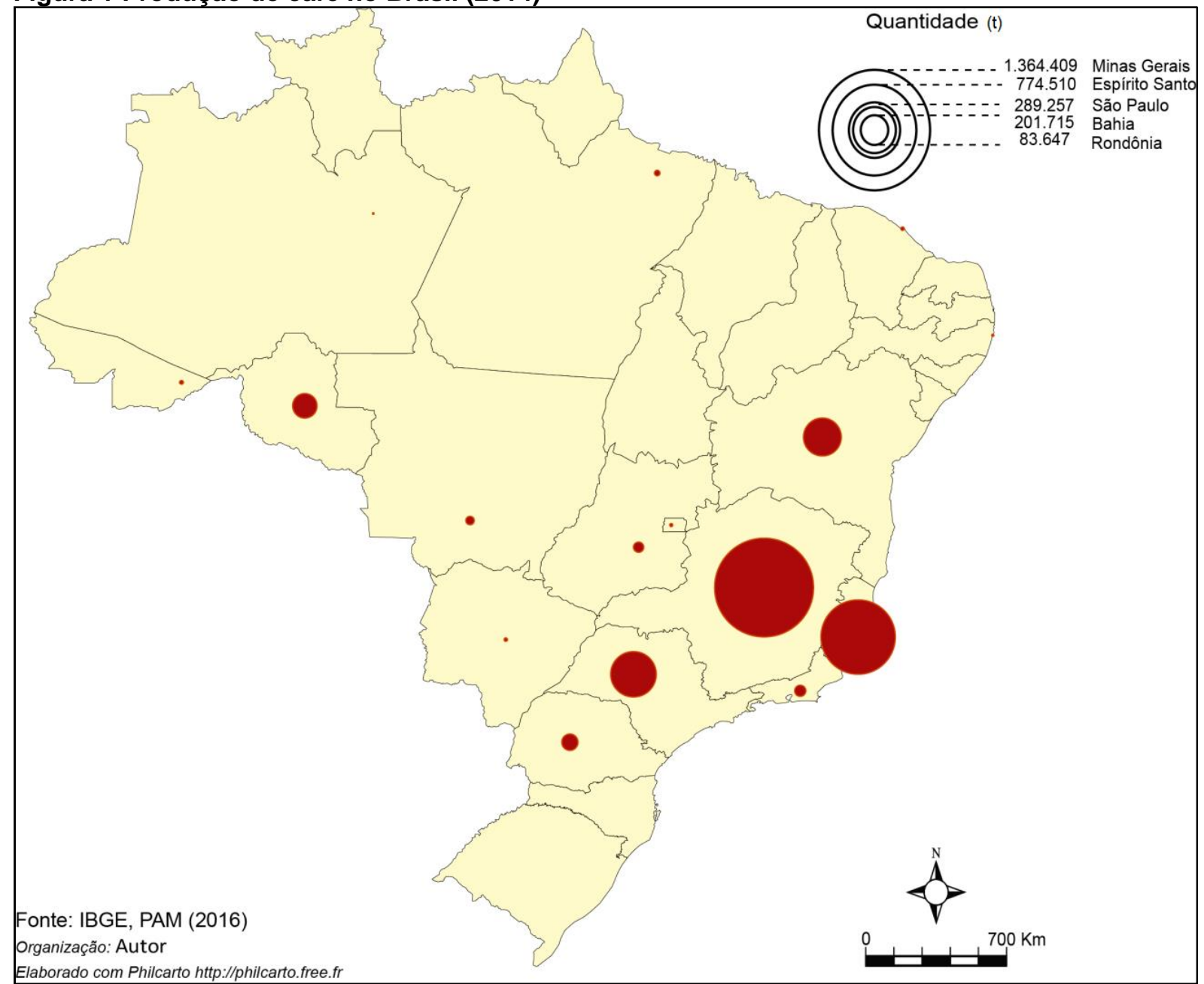

Fonte: IBGE, 2016 (PAM). Org: o próprio autor. (Elaborado com Philcarto)

Apesar da desconcentração produtiva do café (Figura 1), identifica-se que o centro industrial dessa atividade, com as principais torrefadoras do país, permaneceu concentrado na região Sudeste e Sul do país, pois, com a implantação de meios técnicos de transporte e comunicação não era necessário que as indústrias acompanhassem o deslocamento dos 
parques cafeeiros, principalmente por estes terem se deslocados para o oeste/norte do país, como no caso de Rondônia, ficando distante dos grandes centros urbanos consumidores, além da distância dos portos.

Assim, com algumas áreas especializadas na cafeicultura e dispersas pelo território brasileiro se criou fluxos de produção e de informações que articulam todo o processo de industrialização no país, formando o circuito espacial de produção em conjunto com os agentes do círculo de cooperação, sendo estes responsáveis por interligar as diversas etapas do processo, levando aos agentes participantes as informações e normas da produção que atendam às exigências do mercado (SILVEIRA, 2011; FREDERICO; CASTILLO, 2004).

Consoante a essas informações, definimos como integrantes do circuito espacial do café: os agricultores familiares, associações, armazéns, cooperativas, indústrias de torrefação, empresas exportadoras, portos e comércio (atacado e varejo). Assim, da produção ao consumo temos vários agentes envolvidos, porém, todo o processo é subordinado aos interesses do capital nacional e internacional, neste caso do café, as indústrias multinacionais e os seus investidores (agentes hegemônicos).

Portanto, para atender aos interesses dos agentes hegemônicos normas são criadas para cada setor, de forma a melhorar a qualidade do produto e o lucro dessas empresas. Os responsáveis por levarem as regras/normas aos participantes do circuito produtivo são os agentes do círculo de cooperação, compostos por instituições públicas e privadas, que através da assistência técnica, pesquisa, articulação de políticas públicas e etc., promovem a difusão de informações, interligando as diferentes etapas e agentes na participação do mercado do café em escala nacional ou internacional.

No caso específico de Rondônia, o café integra atualmente o circuito espacial de produção, sobretudo em escala nacional, fornecendo matéria prima às principais torrefadoras do país, porém, também tem participação na exportação, principalmente para o México, Bolívia, Espanha e Alemanha (MDIC, 2015). No comércio internacional operam poderosas corporações multinacionais, como as empresas Louis Dreyfus (francesa), Ollan Coffe (indiana), grupo ECOM trading, que instalou a filial EISA Interagrícola no município de Cacoal (Rondônia). A atração dessas empresas resulta da atuação conjunta de diversos agentes do círculo de cooperação que tem atuado na melhoria da produtividade e da qualidade do café rondoniense.

Segundo Veneziano (1996) a negociação do café rondoniense no mercado, dentre muitos aspectos, apresentava as seguintes dificuldades: distância dos grandes centros de consumo, industrialização e exportação, baixo uso tecnológico na produção, cooperativas 
frágeis, linhas de créditos especiais insuficientes, má qualidade do produto e, por fim, pouco conhecimento do mercado por parte dos produtores. Dessa forma, apesar de Rondônia possuir um importante parque cafeeiro, a produção não ocorria de forma organizada, o que dificultava sua participação nacional no circuito espacial de produção do café, inclusive, um dos destaques apontados pelo autor citado era a distância do estado em relação aos principais centros cafeeiros do país, o que demonstra a dificuldade da circulação tanto material como imaterial, além do pequeno incremento tecnológico na produção, resultando em produto de baixa qualidade.

Para solucionar tais problemas, as instituições do círculo de cooperação começaram a atuar em vários campos da atividade produtiva, como no caso da Empresa Brasileira de Pesquisa Agropecuária (Embrapa/Rondônia), que levou em torno de 25 anos para lançar a cultivar BRS Ouro Preto ${ }^{5}$, que apresenta maior produtividade. Porém, a grande participação desses agentes começou principalmente a partir de 2010, com inovações técnico-científicas para a produção de café, como: maior assistência técnica ao produtor com novidades no manejo da planta, transferência de conhecimento de mercado ao agricultor e suporte financeiro por parte de instituições financeiras e do governo estadual.

Diante dessa organização do setor produtivo de café em Rondônia e sua participação no circuito espacial de produção, ainda que de maneira embrionária o resultado começa a aparecer. Segundo o site oficial do Governo do Estado, baseado em dados do Ministério do Desenvolvimento, Indústria e Comércio Exterior (MDIC), entre as safras de 2014 e 2015, houve um aumento de 166\% na exportação do café rondoniense, além da maior parte da produção estadual ser comercializa para Minas Gerais, Paraná, Rio de Janeiro e São Paulo, ficando entre os cinco maiores produtores de café do país, sendo o segundo maior produtor de café conilon (RONDÔNIA, 2015b). Isso é possível em função do aumento de produtividade e melhor circulação da produção no território. Tal resultado também é resposta às exigências das indústrias de café em relação à qualidade técnica do produto agrícola.

Observamos em Rondônia a constituição do circuito espacial de produção do café integrando-se mais fortemente às normas do capital internacional, de modo a aumentar seu poder de exportação, promovendo no espaço agrário a introdução de objetos fixos que permitem o fluxo da mercadoria. Constituem círculos de cooperação que atuam de forma conjunta e interligam os agentes do circuito de produção, compartilhando informações, normas e técnicas, verdadeira solidariedade organizacional (SANTOS; SILVEIRA, 2008) deliberada pelos agentes hegemônicos responsáveis pela industrialização e comercialização do café. 


\section{MODERNIZAÇÃO CAFEEIRA E A TRANSFORMAÇÃO DO ESPAÇO EM RONDÔNIA}

Como visto, Rondônia se apresenta com grande relevância entre os estados produtores de café, integrando-se atualmente ao circuito espacial de produção devido às melhorias em produtividade e qualidade da mercadoria, sobretudo pela incorporação técnico-científica nas práticas agrícolas, através do desenvolvimento de pesquisas e de adoção de inovações no manejo da planta.

A incorporação da ciência ao processo produtivo promove constantes transformações no espaço, deixando-o cada vez mais tecnificado e instrumentalizado, assim, "a agricultura passa, então, a se beneficiar dos progressos científicos e tecnológicos, que asseguram uma produção maior sobre porções de terra menores" (SANTOS, 1994, p. 43). Portanto, a melhor produtividade e qualidade do café rondoniense correspondem à transformação desse espaço produtivo, que apesar de ser rural, é cada vez menos natural, configurando-se como espaço técnico.

Para compreender como ocorre a modernização do processo produtivo do café em Rondônia, torna-se necessário entender como se constituiu esta cultura agrícola, pois, segundo Santos (2014a) o espaço é composto por elementos de vários momentos históricos, em que, alguns são totalmente substituídos e outros resistem ao tempo, coexistindo elementos de períodos diferentes, demonstrando assim sua evolução. Portanto, o espaço agrícola contemporâneo é fruto de processos históricos, remetendo-nos a compreender que "a noção de espaço é assim inseparável da ideia de sistemas de tempo" (SANTOS, 2014a, p. 36). Nesse sentido, analisar os processos históricos da constituição do estado de Rondônia e a introdução da cafeicultura em seu espaço regional se mostra importante para ampliar a leitura do momento atual da produção de café e sua participação no circuito espacial de produção.

Rondônia passou por acelerado processo migratório e de urbanização a partir do início da década de 1970, sendo que o fluxo migratório reduziu no início da década de 1990. Essa geografia foi resultado de projetos do governo federal com a intenção de colonizar áreas da região amazônica com baixo índice demográfico, avançando, portanto, a fronteira agrícola do país, o que resultou em conflitos entre populações com tempos históricos distintos (MARTINS, 2014). Nesse caso, o tempo lento da natureza e de quem nela sobrevive, encontra-se com o tempo rápido ou tempo angustiado do capital e do mercado (LOUREIRO, 2009; SANTOS, 2014b), resultando em uma relação espaço-tempo heterogênea, formado por grupos de pensamentos e costumes diferentes. O tempo lento representa o uso extrativista do espaço, que impera o tempo da natureza, sem a aceleração da produção voltada ao comércio local/regional. A temporalidade evidencia o espaço natural 
(SANTOS, 1994, 2014a, 2014b) com pouca introdução técnica no desenvolvimento econômico e nas formas de trabalho.

Portanto, nesse choque entre diferentes tempos, o predomínio do espaço natural em Rondônia passa a ser incorporado aos ditames da produção voltada ao mercado nacional, tornando-se um espaço técnico, um meio geográfico técnico (SANTOS, 2014b; SILVA 2014, 2015). Segundo Becker (2009), os projetos de expansão na Amazônia foram financiados pelo capital internacional, incluindo áreas isoladas da lógica de mercado, além de demonstrar uma disputa territorial, em que os agentes internacionais ratificam seu poder de influência sobre a Amazônia, um dos últimos espaços naturais que ainda não foi totalmente explorado. (BECKER, 2005, 2009). Dessa forma, Rondônia experimentou grande transformação espacial com a implantação do projeto POLONOROESTE, financiado pelo Banco Mundial, que tinha como objetivo central a pavimentação da rodovia BR-364, que interliga Porto Velho $(\mathrm{RO})$ à Cuiabá $(\mathrm{MT})$. Ainda junto à pavimentação da rodovia, foram criados pelo INCRA (Instituto Nacional de Colonização e Reforma Agrária) assentamentos rurais para receber as inúmeras famílias que migravam de vários estados em busca de terras para viver e produzir. (SILVA, 2014)

Os assentamentos rurais foram fundamentais na mudança da dinâmica espacial rondoniense, substituindo o meio natural com práticas extrativistas, para o meio técnico que incorpora os recursos da natureza à produção e territorialização das famílias nas terras recebidas pelos projetos de colonização do INCRA. Ainda que com pouca estrutura, formaram-se às margens da rodovia centros urbanos ligados às áreas destinadas aos assentamentos, principalmente na parte central de Rondônia (SILVA, 2012), onde os Projetos Integrados de Colonização (PIC's) Ouro Preto, Ji-Paraná e Adolf Rohl assentaram 13.500 famílias nos municípios de Ouro Preto D’Oeste, Jí-Paraná, Cacoal, Presidente Médici, Rolim de Moura, Pimenta Bueno, Espigão D’Oeste e Jarú (BINSZTOK, 2006; SANTOS, 2001).

O interior de Rondônia ficou caracterizado pela introdução da agricultura familiar policultora, responsável pela produção de diversos itens em seus lotes. Um dos principais produtos introduzidos pelos colonos, principalmente na parte central de Rondônia, foi o café e isso não se deu de forma aleatória, mas conforme apontam alguns autores, dois fatores foram primordiais para a implantação da atividade produtiva: o costume agrícola e a possibilidade de territorialização do migrante camponês (BINSZTOK, 2006; MARCOLAN et. al., 2009).

No primeiro caso, parte dos migrantes que chegaram a Rondônia era oriundo do Espírito Santo e do Paraná, tradicionalmente importantes estados produtores de café no 
país. Portanto, esses colonos tinham o costume do trato do café por já terem trabalhado com essa cultura agrícola em seu estado de origem (BINSZTOK, 2006). Já o segundo aspecto importante para a introdução do café em Rondônia é que se trata de uma cultura agrícola perene, portanto, o produtor ao introduzir essa atividade demonstrava sua intenção de instalar-se na propriedade, o que facilitava o recebimento definitivo de posse de terra pelo INCRA (MARCOLAN et. al., 2009), além, é claro, de contar com o trabalho de toda a família, visto se tratar de uma atividade que exige grande quantidade de mão de obra.

Assim, o INCRA distribuía terras aos produtores rurais sem-terra oriundos de outras regiões do país, porém, recomendava o colono a desmatar e produzir para poder então receber o título definitivo, criando neste espaço uma integração ao emergente mercado regional. Destarte, o que ocorreu em Rondônia foi um processo de avanço da fronteira agrícola sobre um espaço natural, incluindo a região à lógica do mercado através de um processo de modernização técnica que substituiu a produção extrativista pela intensificação da agropecuária. Com a inclusão do mercado na produção agropecuária de Rondônia a cafeicultura conseguiu relevância em algumas sub-regiões rondoniense, principalmente na parte Central. Assim, a atividade que inicialmente tinha um papel social na territorialização do camponês passou a assumir importância econômica, alcançando expressivos índices em área destinada à produção durante a década de 1990 e atingindo mais de 220 mil hectares em 2001 (IBGE, 2016).

Apesar do crescimento da área plantada de café durante a década de 1990 e início dos anos 2000, a condição técnica da produção não acompanhava a intensificação tecnológica da agricultura brasileira ocorrida no pós-segunda guerra. Por se tratar de uma nova área agrícola o processo de modernização nessa região se realizou tardiamente. Somente a partir de 2010, através dos agentes do círculo de cooperação, que se intensificaram as ações em torno da modernização técnica da cafeicultura em Rondônia.

Atualmente há em Rondônia um intenso processo de difusão do pacote tecnológico para a cafeicultura, principalmente através da atuação do poder público estadual com a Empresa Estadual de Assistência Técnica e Extensão Rural (EMATER/RO), Secretaria de Agricultura (SEAGRI), Câmara Setorial do Café (sujeita à SEAGRI), mas também com a participação da EMBRAPA no desenvolvimento de novas pesquisas de cultivares e manejo, além de empresas privadas que apoiam o desenvolvimento tecnológico do setor cafeeiro. $O$ resultado desse processo é a modernização produtiva do café, com novas técnicas de manejo, como: análise do solo, calagem, adubação, uso de agrotóxicos, poda e desbrota, além da instrumentalização com novos objetos que até pouco tempo eram estranhos ao meio rural rondoniense, como a irrigação artificial (Figura 2). Dessa forma, a produção passa 
a atender as normas do capital industrial, resultando em uma participação com maior escala de abrangência, atuando no cenário nacional e internacional.

Figura 2: Cafezal irrigado em Rondônia

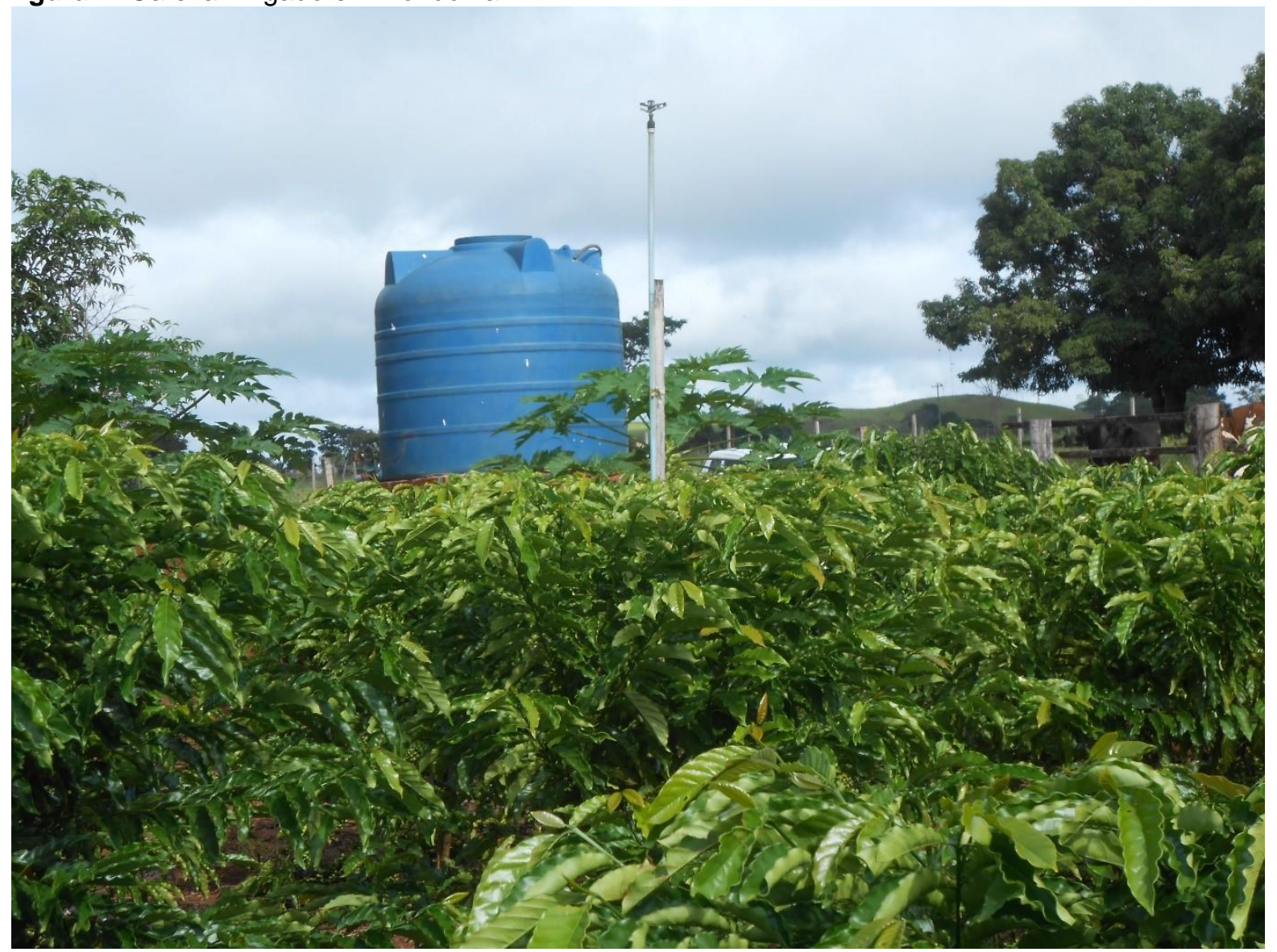

Fonte: Trabalho de campo. Autor (2017).

Além das inovações técnicas a modernização da cafeicultura rondoniense tem como principal instrumento a substituição de plantas cafeeiras tradicionais, cultivadas através de semente e sem manejo, por mudas clonais, criadas a partir do cruzamento genético de diversas plantas com boa resistência às pragas e às intempéries edafoclimáticas, apresentando boa produtividade, o que possibilitou ganhos econômicos ao obter melhor aproveitamento espacial. Neste caso, o entendimento por modernização agrícola acompanha o que aponta Graziano Neto (1985), em que, não são somente as inovações técnicas que representam uma produção moderna, mas também o interesse capitalista na tecnificação da atividade, sendo que, a introdução de novos objetos no espaço produtivo tende a beneficiar o controle do capital sobre aquela porção do espaço.

Através da influência dos agentes do círculo de cooperação, o capital industrial incentiva os agricultores familiares a adotarem mudas clonais que proporcionem elevados 
índices de produtividade. O único exemplo de cultivar clonal certificado em Rondônia é o BRS Ouro Preto criado pela EMBRAPA, que apresenta bons resultados adaptado às condições de relevo e clima do estado, com rendimento de 70 sacas de $60 \mathrm{~kg}$ por hectare, e em caso de irrigação, pode atingir mais de 110 sacas por hectare (EMBRAPA, 2015). Por questão de comparação, a produção em sistema tradicional, através de semente e sem manejo da planta, apresenta um rendimento de 11 a 12 sacas por hectare (OLIVEIRA; ARAÚJO; ARAÚJO, 2011). Apesar de ser o único certificado, o BRS Ouro Preto não é o único cultivar clonal plantado em Rondônia, pois, devido à demora nas pesquisas para criação de um clonal no estado, viveiristas fizeram seu próprio cultivar através do cruzamento das plantas que apresentassem melhores desempenhos, resultando em diversos tipos de plantas clonais na produção local.

Destarte, percebemos que a introdução tecnológica ao processo produtivo de café em Rondônia, através dos agentes do círculo de cooperação, tem chegado aos produtores, o que tem permitido grande avanço na produtividade do estado, além de maior relevância dessa atividade agrícola no cenário nacional, devido, principalmente, a melhor qualidade da produção, o que resulta também em melhores rendimentos aos envolvidos na cafeicultura. Com a intensificação produtiva da agricultura o espaço torna-se mais tecnificado com a presença de inúmeros objetos que contribuem para uma produção mais acelerada, o que atende aos interesses do mercado nacional.

\section{MODERNIZAÇÃO TÉCNICA E SUBORDINAÇÃO DA AGRICULTURA FAMILIAR}

Historicamente a cafeicultura apresentou importante papel social ao contribuir para a territorialização do agricultor familiar recém-chegado em Rondônia. Além disso, permitia o trabalho a todos os integrantes da família devido a necessidade de grande mão de obra exigida pela atividade, evitando o êxodo rural dos mais jovens e mantendo a sucessão familiar no campo.

A introdução da atividade cafeeira em Rondônia não teve somente o papel social de contribuir para a permanência das famílias no campo, mas também tratou-se de uma opção cultural daqueles que chegavam às novas terras. Dessa forma, apesar do início da integração da região ao mercado, os agricultores conseguiam ter autonomia na escolha de sua produção, pois essa não estava subordinada ao circuito superior da economia, dado sua abrangência em escala local.

No decorrer do tempo a atividade cafeeira começou a alcançar maiores escalas produtivas, chamando atenção do mercado nacional, porém, com baixa tecnologia não atendia todas as exigências de qualidade, resultando em preços menores. De certa forma, a desvantagem não gerava grandes impactos econômicos aos produtores, visto que a maioria 
dos cafezais já havia sido plantado há bastante tempo, não proporcionando muitos gastos às famílias. Somente a partir de 2010 a cafeicultura de Rondônia iniciou um intenso processo de modernização técnica em seu desenvolvimento, principalmente através da atuação dos agentes do círculo de cooperação, o que tem levado os agricultores familiares a subordinarem-se ao capital comercial e industrial.

Graziano da Silva (1981) discorre sobre a importância da introdução tecnológica como forma do capital controlar o processo produtivo, além de possibilitar maiores lucros sobre a produção. O autor aponta ainda que a modernização gera a subordinação do produtor ao capital devido a necessidade de atender às suas exigências. Acompanhando a assertiva, Santos e Silveira (2008) apontam para o uso corporativo do espaço, em que os agricultores familiares que possuem relações de trabalho não-capitalista são "cooptados" à trabalharem sob o controle regional das grandes empresas. Assim, o espaço agrário familiar passa a compor a lógica das grandes corporações detentoras do capital industrial, tornando esse grupo social sujeitos vulneráveis no âmbito do circuito produtivo. Nesse sentido, a verticalização das relações produtivas (SANTOS, 2014b) contribui para a dominação do território pelo capital, em que os agentes controladores do processo que estão na parte superior da economia impõem suas regras aos agricultores familiares, que estão na base do circuito.

A política neoliberal do fim da década de 1980 e início de 1990 é um exemplo da subordinação do agricultor familiar produtor de café, quando houve a desregulamentação estatal do mercado, com o fim do Acordo Internacional do Café (AIC), ou seja, o controle das negociações passou do protecionismo aos produtores, para a exploração dos compradores (FREDERICO, 2013). Para exemplificar tal situação, entre os anos de 1970 e 1990, os países produtores de café, subdesenvolvidos, retinham metade do valor total das negociações com as empresas multinacionais, sejam torrefadoras ou exportadoras de grãos. Desse valor, em torno de $30 \%$ ficava com o produtor, ou seja, este era um importante agente dentro das tomadas de decisões sobre o mercado do café. Porém, a partir do fim do AIC, em 1989, os países importadores de café passaram a ficar com $75 \%$ da renda obtida na negociação, enquanto países produtores somente com 25\%, e desses, aproximadamente, somente $13 \%$ ficou com os produtores. Com a regulação do preço de mercado nas mãos das grandes empresas, o agricultor ficou exposto às lógicas globais do mercado capitalista, perdendo seu poder de influência (FREDERICO, 2013).

Diante dessa condição do mercado do café, para manter-se na atividade o agricultor é obrigado a adaptar-se às exigências impostas pelos agentes hegemônicos, investindo em modernização tecnológica para aumentar a produtividade e a qualidade do produto. Porém, por se tratar, em sua grande maioria de agricultores familiares descapitalizados, normalmente recorrem ao crédito rural para implantar o chamado "pacote tecnológico". No 
entanto, mesmo sendo assistidos pela EMATER, estão sujeitos às mudanças de cenário que os prejudique, como: intempéries edafoclimáticas, doenças e pragas na plantação, oscilações do preço do produto na bolsa de valores e etc. Assim, caso ocorra algum problema no momento da produção, o único a sofrer as consequências é o produtor, que não conseguirá pagar o investimento e ficará ainda mais sujeito ao mercado, como ocorreu em fevereiro de 2017, quando a Câmara do Comércio Exterior (CAMEX) autorizou a importação de 1 milhão de sacas de $60 \mathrm{Kg}$ do café robusta, entre fevereiro e maio desse ano, de modo a atender os interesses do capital industrial (ABICS, 2017). Nesse caso, o agricultor familiar descapitalizado e que teve que recorrer a créditos financeiros para se modernizar e atender as exigências do mercado acaba tendo perdas, pois, com o aumento da oferta de café, o valor pago pela saca acaba reduzindo.

No caso específico da cafeicultura em Rondônia, criou-se uma psicosfera (SANTOS, 2014b) em torno da melhoria tecnológica da atividade e dos possíveis rendimentos a serem extraídos, sobretudo, nas regiões produtivas de café no estado: Região de Cacoal, conhecida como 'Capital do Café'; Região da Zona da Mata e Vale do Guaporé, conhecida como a região de investimento tecnológico avançado; e a Região de Machadinho D'Oeste, frente de avanço da cafeicultura para o norte do estado (SANTOS; SILVA, 2015) (Figura 3).

Figura 3 Regiões Produtivas de Café em Rondônia

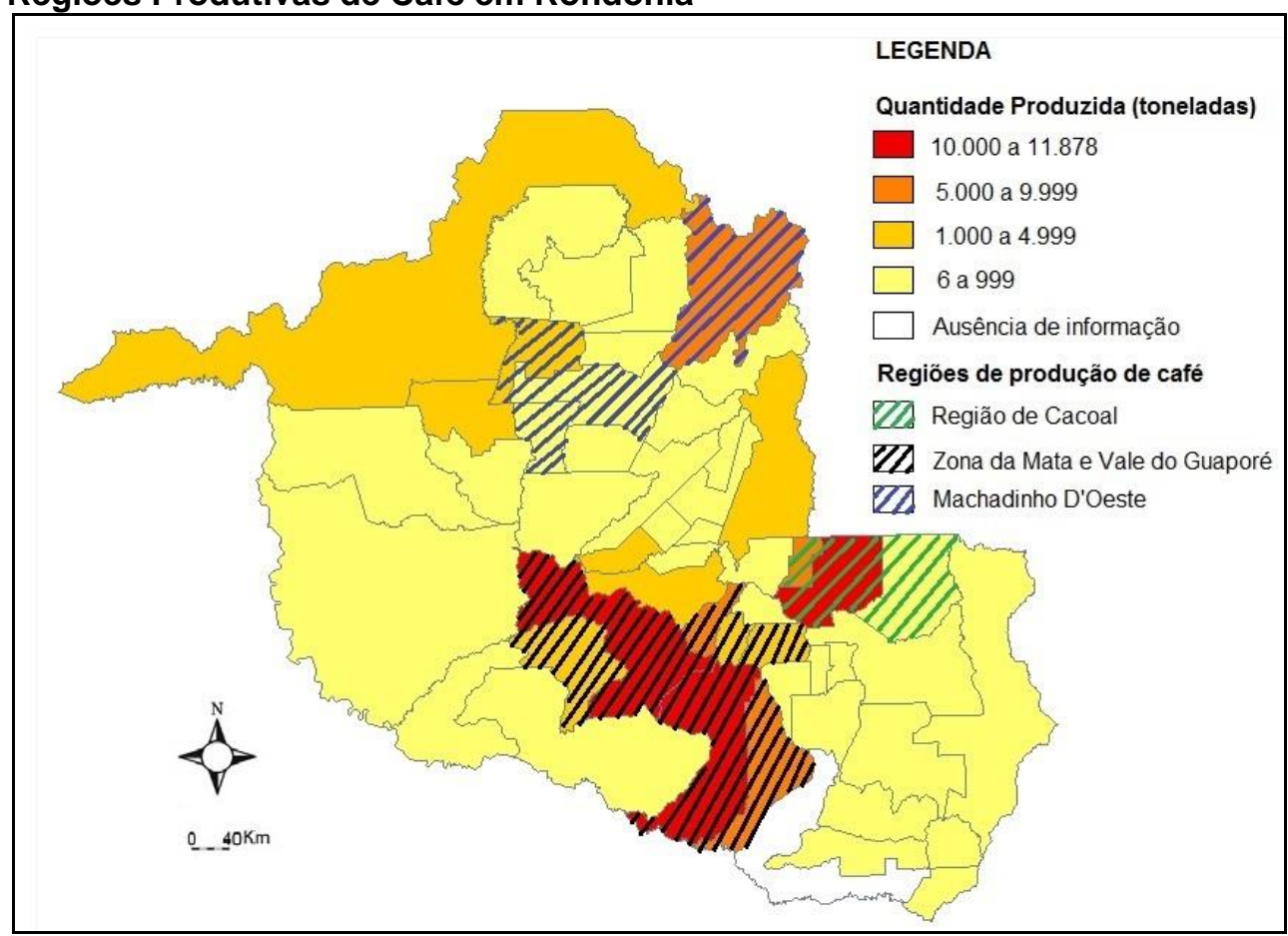

Fonte: IBGE, 2016 (PAM). Org. Autor, elaborado com Philcarto.

Para incentivar a adoção das inovações para o setor cafeeiro, o Governo do Estado tem investido em uma vitrine tecnológica para demonstrar ao agricultor as melhorias para a 
produção, com o fornecimento de calcário e em alguns casos mudas, além da assistência técnica. Esse conjunto de ações do poder público tem incentivado maior adesão por parte dos produtores à cafeicultura modernizada. Além deste incentivo, o anúncio em março de 2015 de que a Nestlé estaria interessada na compra do café rondoniense ampliou ainda mais as expectativas dos produtores em conseguir bons negócios em relação à produção (RONDÔNIA, 2015a), ou seja, através da psicosfera em torno da modernização tecnológica na cafeicultura, o Estado atua favorecendo a sujeição da agricultura familiar aos interesses do mercado, tratando-os como agentes do agronegócio, quando na verdade são agricultores trabalhando com algum grau de tecnologia, mas, sobretudo, constituem o trabalho familiar ou a agricultura familiar.

Neste caso, o Estado age para estimular a produção visando atender a demanda nacional e internacional. Além disso, o produtor de café estimulado pela propaganda de comercialização com a Nestlé e outras indústrias ou exportadoras, acaba por aceitar sua subordinação às normas impostas, à solidariedade organizacional do capital (SANTOS; SILVEIRA, 2008). Como exemplo, assinalamos a palestra realizada pelo representante da Nestlé, senhor Pedro Malta, no dia 10 de abril de 2015, na Câmara Municipal de Cacoal, durante o evento de lançamento da Lei n`3.516 de 17 de março de 2015, que instituiu o dia do início da colheita do café em Rondônia. Nesta ocasião, o palestrante questionou o uso de várias mudas clonais pelos produtores e os seus métodos de secagem do café, apontando para a necessidade de um padrão que deve ser estipulado pela empresa. Assim, o agricultor deve se adequar às exigências e se sujeitar as normas impostas caso queira comercializar sua produção para a empresa. Da mesma maneira outras empresas atuam apontando para os produtores suas normas e sujeitando os mesmos à sua dinâmica de mercado.

Segundo Frederico e Barone (2013), uma das formas de eliminar essa subordinação ao capital e participar mais efetivamente do circuito espacial produtivo seria eliminar intermediários entre a produção, industrialização e o consumo. Para Marquez (2008), a produção familiar, em sua função subordinada, não consegue interferir na definição dos preços da safra, sendo que isso só se modificaria com uma mobilização e organização política em defesa de seus interesses. No caso da cafeicultura de Rondônia seria necessária uma organização coletiva, com a formação de cooperativas ou associações que contribuíssem na comercialização da safra de forma mais justa com a indústria torrefadora, ou até mesmo com a instalação de agroindústrias do café, de forma que conseguissem maior protagonismo e poder de negociação no mercado, não estando sujeitos aos mandos do capital hegemônico do setor.

Apesar desse entendimento, a organização em associações rurais ainda é limitada na cafeicultura rondoniense, contribuindo apenas com a possibilidade de uso compartilhado 
de maquinários e para beneficiamento do café, sem interferir na negociação da safra, que acaba ocorrendo de forma individualizada com os representantes do capital comercial local, que por sua vez, intermediam a produção estadual às grandes indústrias torrefadoras nacional e/ou internacional, mantendo a atividade familiar subordinada ao mercado.

\section{CONCLUSÃO}

A cafeicultura é uma importante atividade agrícola desenvolvida em Rondônia, com relevância no cenário nacional. Dessa forma, este trabalho buscou compreender as dinâmicas espaciais e sociais promovidas a partir do desenvolvimento desta cultura agrícola no estado.

Com o advento da globalização e as melhorias nos meios de transportes e de comunicação, intensificou-se a divisão territorial do trabalho e consequentemente as especializações produtivas, ficando assim as várias etapas da produção distribuídas territorialmente, resultando em maior circulação, tanto material como imaterial. Essa dinâmica passou a ocorrer na cafeicultura de Rondônia nos últimos anos, por ser uma área que recentemente foi integrada às lógicas capitalistas de produção voltadas ao mercado na escala nacional. Com a introdução técnico-científica no meio produtivo e a melhoria de qualidade e produtividade, Rondônia passou a integrar o circuito espacial de produção de café, participando na base desse circuito através da agricultura familiar e do capital comercial, que são os responsáveis por intermediar o produto local com as grandes indústrias torrefadoras multinacionais, localizadas, principalmente, no Sul e Sudeste brasileiro. Além disso, participa no fornecimento de matéria prima para o exterior através da exportação, que apesar de pequena tem atraído corporações mundiais para o estado.

A participação no circuito de produção do café foi possível graças as articulações dos agentes responsáveis pelo círculo de cooperação, que integram as diversas etapas da produção através de pesquisas de melhorias no cultivar, assistência técnica, financiamento ou até mesmo através dos incentivos promovidos pelo governo do estado. As melhorias inseridas na modernização do parque cafeeiro de Rondônia elevaram sua produção, ficando entre os cinco estados com maior safra no país, além de segundo maior do café tipo conilon. Tais melhorias no cultivar atendem aos interesses dos principais agentes do circuito de produção de café, o que permite que o produto seja comercializado com grandes indústrias do ramo, além de aumentar as exportações do produto.

O resultado da introdução científica na produção de café não resulta somente em aspectos econômicos. Para haver a circulação do produto é necessária a implantação de objetos no espaço geográfico, tornando este mais artificializado e integrado ao tempo acelerado do capital, diferente do tempo lento do espaço natural ao qual Rondônia vivenciara até a década de 1970. 
A cafeicultura de Rondônia também apresenta um papel social e cultural relevante para o agricultor familiar, que a partir dessa atividade manifestou sua territorialização na região. Com a modernização técnica da agricultura os produtores familiares são impelidos a se integrar ao mercado, produzindo cada vez mais e com melhor qualidade, adotando técnicas exigidas. Porém, como não são capitalizados necessitam recorrer ao crédito bancário, o que os deixam vulneráveis às oscilações do mercado futuro das bolsas de mercadorias, além da possibilidade de intempéries edafoclimáticas prejudicarem suas produções, sendo eles os únicos a correrem o risco de perdas.

Há assim uma subordinação do agricultor familiar ao capital, através de normas impostas de forma vertical, em que o trabalhador adéqua sua produção e o seu espaço agrícola às regras exigidas pelos agentes hegemônicos. Por outro lado, os próprios agricultores não conseguem identificar essa subordinação e, consequentemente, não se organizam coletivamente de forma a alcançar maior protagonismo dentro do circuito produtivo, o que os mantém fragilizados aos ditames do capital industrial.

Destarte, vemos que a atividade cafeeira no estado de Rondônia tem visado a modernização de forma a se manter com importância no circuito espacial de produção em escala nacional e até mesmo alcançar o cenário internacional. Porém, esse processo é resultado da atuação dos agentes do círculo de cooperação que atuam em favor do mercado globalizado, promovendo transformações espaciais no setor agrícola rondoniense, que cada vez mais se torna tecnificado, além de subordinar a agricultura familiar às regras dos agentes hegemônicos, controladores do capital, ampliando, assim, o uso corporativo do espaço.

\section{REFERÊNCIAS}

ABICS. Importação de café conilon é inevitável, avalia indústria de solúvel. 2017. Disponível em: <www.abics.com.br> Acesso em: 03 de mar. 2017.

BECKER, B. K. Geopolítica da Amazônia. Estudos Avançados, São Paulo, v. 53, n. 19, p. 71-86, 2005. Disponível em: <https://goo.gl/fFAjbA> Acesso em: 05 nov. 2015.

Amazônia: Geopolítica na virada do III milênio. Rio de Janeiro: Garamond, 2009.

BINSZTOK, J. Agricultura familiar na Amazônia: o contexto da cafeicultura no centro de Rondônia. Geografias, Belo Horizonte, v. 02, n. 1, p. 22 - 33, jan./jun. 2006. Disponível em: <https://goo.gl/LghCtU> Acesso em: 17 set. 2014.

CASTILLO, R.; FREDERICO, S. Espaço geográfico, produção e movimento: uma reflexão sobre o conceito de circuito espacial produtivo. Sociedade \& Natureza, n.3, v. 22, Uberlândia, dez. 2010, p. 461-474. Disponível em: <https://goo.gl/Xj6VEr> Acesso em: 18 ago. 2015.

CECAFÉ, Conselho dos Exportadores Mundiais de café do Brasil. Exportações mundiais. Out. 2016. Disponível em: <https://goo.gl/e1T47h> Acesso em: 02 de fev. de 2017. 
EMBRAPA. Nova cultivar de café tem potencial para mudar realidade do campo na Amazônia. EMBRAPA, 2015. Disponível em: <https://goo.gl//hJPbx> Acesso em: 27 de nov. de 2015.

FREDERICO, S. Lógica das commodities, finanças e cafeicultura. Boletim Campineiro de Geografia, v. 3, n. 1, Campinas, 2013. Disponível em: <https://goo.gl/x5mZfY> Acesso em: 18 ago. 2015.

FREDERICO, S.; BARONE, M. Circuito Espacial Produtivo e Círculos de Cooperação do café fairtrade: análise da associação dos agricultores familiares do córrego D'antas (ASSODANTAS), Poços de Caldas/MG. In: Simpósio de pesquisa dos cafés do Brasil, 8, 2013, Salvador. Anais... Salvador: SBICafé, 2013. p. 7-18. Disponível em:

<https://goo.gl/VzNnnh> Acesso em: 18 de ago. de 2015.

FREDERICO, S. e CASTILLO, R. Circuito espacial produtivo do café e competitividade territorial no Brasil. Ciência Geográfica, v. 10, n. 3, Bauru, 2004.

GRAZIANO DA SILVA, J. Progresso técnico e relações de trabalho na agricultura. São Paulo: HUCITEC, 1981.

GRAZIANO NETO, F. Questão agrária e ecologia: Crítica da agricultura moderna, São Paulo: Brasiliense, 1985.

IBGE. Pesquisa Agrícola Municipal, 2016. Disponível em: <https://goo.gl/oaVmvH> . Acesso em: 15 jan. 2016.

LOUREIRO, V. R. Amazônia no séc. XXI: de fronteira econômica do país a fronteira do mundo. In: A Amazônia no séc. XXI: as novas formas de desenvolvimento. São Paulo: Empório do livro, 2009, p. 67-86.

MARCOLLAN, A. L. et. al. Cultivo dos cafeeiros Conilon e Robusta para Rondônia. $3^{\circ}$ ed. Porto Velho: Embrapa Rondônia: EMATER-RO, 2009.

MARQUEZ, M. I. M. Agricultura e campesinato no mundo e no Brasil: um renovado desafio à reflexão teórica. In: PAULINO, E. T.; FABRINI, J. E. (Org.). Campesinato e territórios em disputa. São Paulo: Expressão Popular. 2008. p. 49 - 79.

MARTINS, J. de S. Fronteira: a degradação do outro nos confins do humano. $2^{\circ}$ ed. $2^{\circ}$ reimp. São Paulo: Contexto. 2014.

MDIC. Balança comercial brasileira: municípios, Cacoal/RO. 2015. Disponível em: <https://goo.gl/P32Tql> Acesso em: 20 de dez. 2015.

OLIVEIRA, S. J. de M., ARAÚJO, L. V., ARAÚJO, T. G. Avaliação econômica em sistemas de produção de café em Rondônia. In: Simpósio de pesquisa dos cafés do Brasil, 7, 2011, Araxá, Anais...Consórcio pesquisa café, p. 1-5. Disponível em: <https://goo.gl/5NUoWp> Acesso em: 20 de abr. de 2015.

ORTEGA, A. C. e JESUS, C. M. de. Café e Território: a cafeicultura no Cerrado Mineiro. Campinas: Alínea, 2012

RONDÔNIA. Nestlé quer comprar café de Rondônia, primeiro produtor da região Norte, SEAGRI, 2015a. Disponível em: <https://goo.gl/yGdQUi> Acesso em: 15 jul. 2015.

Exportação de café em grão sobe 166\% neste ano em Rondônia, aponta

Ministério do Desenvolvimento. IDARON, 2015b. Disponível em: <https://goo.gl/dVG4cT> Acesso em: 20 de nov. de 2015.

SANTOS, C. A fronteira do Guaporé. Porto Velho: EDUFRO, 2001.

SANTOS, M. Metamorfose do Espaço Habitado. 3 ed. São Paulo: HUCITEC, 1994.

Espaço e método. $5^{\circ}$ ed. $2^{\circ}$ reimp. São Paulo: EDUSP, 2014a. 
A natureza do espaço: técnica e tempo. Razão e emoção. 7. reimp. $4^{\circ}$ ed. São Paulo: EDUSP, 2014b

SANTOS, M.; SILVEIRA, M. L. O Brasil: Território e sociedade no início do século XXI. $11^{\circ}$ ed. Rio de Janeiro: Record, 2008.

SANTOS, T. R. S.; SILVA, R. G. da C. Campesinato e o café na Amazônia Ocidental: uma análise territorial dos núcleos cafeeiros no estado de Rondônia. In: Simpósio Internacional de Geografia Agrária, 7, 2015, Goiânia, Anais...Goiânia:UFG, 2015, p. 3897-3911. CDROOM.

SILVA, R. G. da C.. Das margens do Madeira ao interior da floresta: percursos da formação sócioespacial de Rondônia (1970-1995). In: ALMEIDA SILVA, A; NASCIMENTO SILVA, M. G. S; SILVA, R. G. C. (Orgs.) Colonização, Território e Meio Ambiente em Rondônia: Reflexões geográficas. 1ed. Curitiba: Editora SK, 2012, v. 1, p. 58-82.

Espaço, Sociedade e Natureza em Rondônia. Revista GeoAmazônia, Belém, n. 2, v. 01, p. 144-165, jan./jun. 2014. Disponível em: <https://goo.gl/4qgKkN> Acesso em: 18 set. 2015.

Amazônia Globalizada: da fronteira agrícola ao território do agronegócio - o exemplo de Rondônia. Confins, n. 23, 2015. Disponível em: <https://goo.gl/nMO6Ca> Acesso em: 09 nov. 2015.

SILVEIRA, M. L. Território usado: Dinâmicas de especialização, dinâmicas de diversidade. Ciência Geográfica, Bauru, v. 15, n. 1, p. 4-12. jan/dez. 2011. Disponível em: <https://goo.gl/gmidgW> Acesso em: 20 dez. 2015.

VENEZIANO, W. Cafeicultura em Rondônia: situação atual e perspectivas. Porto Velho: EMBRAPA, 1996.

\section{AGRADECIMENTOS}

Agradecimento a CAPES pela disponibilização de bolsa de estudos, ao Instituto Federal de Rondônia pelo afastamento das atividades para dedicação exclusiva à capacitação, e ao Grupo de Pesquisa Gestão do Território e Geografia Agrária da Amazônia GTGA/LAGET/UNIR.

\footnotetext{
${ }^{1}$ Mestre em Geografia, Professor no Instituto Federal de Rondônia (IFRO) - Campus Cacoal, Av. das Comunicações, 3930, bl. 4, cs 38, Villa Flora, CEP - 76965-492, Cacoal/RO. tiago.santos@ifro.edu.br

2 Doutor em Geografia, Professor no Departamento de Geografia da Universidade Federal de Rondônia, Rua: Daniela, 1016, Três Marias, CEP - 76812-656, Porto Velho/RO. rgilson@unir.br

${ }^{3}$ Para Santos (2014b) a psicosfera, está relacionada ao fornecimento de normas, atuando no ramo das ideias e estimulando o imaginário na adoção das regras impostas pelos controladores do sistema produtivo.

${ }^{4}$ Os elementos fixos são os objetos fixados em algum lugar do espaço, permitindo ações que modificam estes lugares conforme os interesses daqueles que o instalaram. Os fluxos são resultados dessas ações, em que o uso do fixo permite maior fluidez do produto no espaço.

${ }^{5}$ Informação obtida através do Sr. Alexandro Lara Teixeira, Secretário Executivo do Comitê Técnico Interno da EMBRAPA/RO, através de entrevista concedida ao autor em 06 de jul. de 2016.
} 